\title{
Friction Stir Welding of Stainless Steel 304: A Survey
}

\author{
Pushp Kumar Baghel \\ Research Scholar, Department of Mechanical Engineering, Delhi Technological University, Delhi, India
}

\begin{abstract}
Stainless steel 304 is a class of iron based materials which has certain resistance to rusting and to corrosion in some environments. Due to its properties, it is the most widely used material in the engineering applications. Most of stainless steel welding to this date is done by fusion welding. This survey revealed that very little amount of work has been done with few exceptions only mechanical properties have been characterized.
\end{abstract}

\section{Introduction}

Friction Stir Welding is one of the emerging welding techniques and due to its advantages over fusion welding technique it has drawn attention of various researchers around the world. Literature review has indicated that various metals and their alloys have been successfully welded by this process but FSW of Stainless steel 304 has not progressed as rapidly as for aluminum and other metals because of various reasons some of which are given below:

i. The material from which the tool is made has to survive much more strenuous conditions because of strength of steel and high softening temperature of steels.

ii. The consequences of phase transformations accompanying FSW have not been studied in sufficient depth.

iii. The variety of steels available is much larger than for any other alloy system, requiring considerable experiments to optimize the weld for a required set of properties.

Since, Stainless steel 304 it is one of the most widely used materials in the engineering application. Researchers around the world are studying various aspects of FSW like tool design, rotational speed, welding speed, tool material etc, and their effect on the welding of stainless steel 304.

FSW of stainless steel is premature with only few exceptions: only mechanical properties have been characterized. Most reports are limited to simple bend, tensile and hardness tests.

Zhu and Chao [1] studied the variation of transient temperature and residual stress in a friction stir welded plate of 304L stainless steel. Using experimental records of transient temperature at specific locations during the FSW process, an inverse analysis method for thermal numerical simulation was developed. They also determined the residual stresses in the welded plate. Further they studied effect of fixture release on residual stresses and it was found out that residual stress in the welds after fixture release decreased significantly as compared to those before fixture was released.

Hwan et. al [2] studied the microstructures of Friction Stir Welded stainless steel 304 which was carried out using PCBN tool. They also examined the microstructural evolution during FSW. It was observed that stir zone (SZ) and TMAZ showed typical dynamically recrystallized and recovered microstructures as shown in Figure 1[2].
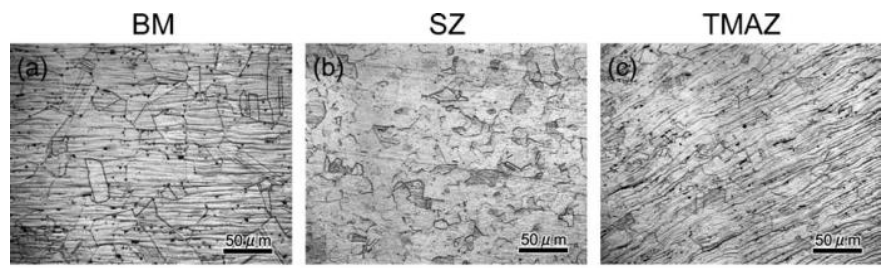

Figure1- Optical micrograph - base material, stir zone and thermomechanically affected zone.

Further, microstructural observation also revealed the formation of sigma phase with numerous stacking faults which was formed at the advancing side of the stir zone. They also found that during FSW rapid formation of sigma phase took place due to the transformation of austenite to delta-ferrite in the stir zone which occured due to high strain and dynamic recrystallization during the FSW [2].

Reynolds et. al [3] compared the tensile properties, optical microstructure, and residual stresses of two friction stir welds in 304 stainless steel produced at two different tool rotation rates. They determined that for 
given welding speed, higher tool rotation was observed to correspond to a higher energy input per unit length of weld. Further, they showed that lower energy input resulted in:

a) Lower weld temperature,

b) Finer weld nugget grain size, and

c) Greater weld overmatching compared to the higher energy input weld.

They also found that residual stresses produced in FSW of 304 stainless steel are similar in character and magnitude to those resulting in fusion welding. Further, they concluded that magnitude of longitudinal stress is limited by the base metal yield strength for both tool rotation rates. The bending moment about the longitudinal axis was also observed when sign of transverse residual stress changes from tensile at the crown to compressive at the root.

Kokawa et. al [4] studied the microstructural evolution and hardness distribution in the welds of $2 \mathrm{~mm}$ and $6 \mathrm{~mm}$-thick 304 austenitic stainless steel plates. It was found that hardness of the SZ was higher than that of the base material and the maximum hardness was located in TMAZ. The higher hardness of TMAZ is due high density of dislocations and sub-grains. Further, observation also revealed that ferrite and sigma phase were formed in austenite matrix in the SZ depends on the cooling rate during FSW.

Meran and Kovan [5] studied the microstructural features of 304 stainless steel welded plates.. Welding was performed on $11 \mathrm{KW}$ vertical milling machine on $2.5 \mathrm{~mm}$ plate. The tool used was tungsten-based alloy they found out that tungsten carbide tool yielded good results. They also observed that best welding appearance was obtained when tool dipping angle was $1.45^{\circ}$. It was also revealed that cold working conditions are not suitable for FSW of stainless steel. Higher strength of welding was observed when travel speed is $63 \mathrm{~mm} / \mathrm{min}$ and rotational speed is $1000 \mathrm{rpm}$

Not much literature is available on FSW of stainless steel 304 with regard to tool design and specific tool material. This may be because it possesses very high softening temperature and its strength is also very high. Under these circumstances the tool design, tool material and its fabrication is the major difficulty. Although FSW of stainless steel 304 has been carried out before but the technology might have been patent. That's may be the reason that on stainless steels not much literature review is available.

India is one of the fastest developing countries in the world. Due to the eco-friendly nature of FSW it has found important position in India. Though in initial phases, many research and academic institutions are undertaking to FSW but most literature available in Indian context is on $\mathrm{Al}$ alloys. Attempts have been made to weld mild steel at places like BARC Mumbai, IISC Banglore, Annamalai University, and NIT Trichi. Among some of the breakthrough researches in India, Welding Laboratory, IIT Delhi, is doing pioneering work under the leadership of Professor S. Pandey [6, 7].

\section{Conclusion}

In the present study, an attempt has been made to study the feasibility of using FSW for welding of stainless steel 304 and also to study the effects of FSW parameters on the microstructure of welded specimen.

\section{Scope for Future Work}

Although the suitability of using FSW for stainless steel 304 has been explored in the present work. There are still many other aspects of FSW that need to be addressed in future. In terms of scope of future work the following suggestions are proposed:

- Rigorous experimental investigation needs to be carried out to obtain optimal FSW parameters.

- An appropriate tool design needs to be developed by taking into consideration factors such as metal flow, heat flow and power requirement.

\section{References}

1. Zhu X.H, Chao Y.J, (2004) Numerical simulation of transient temperature and residual stresses in Friction stir welding of 304L stainless steel. J Mater Process Technol 46:263-272.

2. Seung Hwan C, Yutaka S, Hiroyuki Kokawa, Kazutaka Okamoto, Satoshi Hirano (2003) J Scripta Materialia 49:1175-1180.

3. Reynolds A.P, Wei Tang, Gnaupel-Herold T, Prask H (2003) Structure, properties, and residual stress of 304 L stainless steel, friction stir welds. J Scripta Materialia 48:1289-1294.

4. Kokawa H, Hirano S (2005) Microstructures in friction stir welding of 304 austenitic stainless steel. 56:234-236.

5. Meran C, Kovan V, Alptekin A (2007) Friction Stir Welding of AISI 304 austenitic stainless steel. 38:123-124.

6. Pandey S, Grewal G et al. (2003) "FSW: a recent trend in welding" in national workshop on welding technology in India - Present status and future trends, SLIET, Punjab, pp 91-97.

7. Khan Zaheer, Pandey Sunil, Prasad Rajesh, Prasanna L (2009) "Friction Stir Welding of Mild Steel”. 